\section{The Origin of Life.}

ALthough to the evolutionist it must necessarily appear more than probable that at some time or other non-living matter has by evolution acquired the properties of life, and to him the only question is as to how this has come about, yet, for all that, he has been in the habit of admitting that the complete failure of all experiment in this direction makes the negative evidence very strong indeed. My present object is to suggest that the negative evidence, so far from being strong, is so weak that perhaps it can hardly be said to exist.

In the experiments the first step has always been, and, so far as one can see, must always be, to destroy all existing life and all existing germs of life. Suppose the agent to be heat. How does the experimenter know that the very means he employs to destroy in living matter the property of life are not equally efficacious in destroying the peculiar property or properties of matter that is just on the point of transmutation? For all that we certainly know to the contrary, dead matter may be changing into living every day in every pool, especially every warm pool, on the face of the earth. If so, the difference between the last state of the non-living and the first state of the living must, by the evolutionist's hypothesis, be extremely small; and it is probable-to my mind most probable--that both would be similarly affected by an unusual degree of heat, or whatever other agent is calculated to destroy life; the precaution eliminating life and its potentiality at one stroke. But the value of the negative evidence is precisely in inverse proportion to this probability. If the probability is thought great, the negative evidence will necessarily be thought small. I submit that the probability is very great indeed, and consequently that we are pretty much in the same position as to the possible evolution of life from non-living matter as we should have been if no experiments had been made. Certainly, so far as the logic of the matter is concerned, there is no need yet to consider the hypothesis of life having been imported here from another planet.

Birmingham, October 25. George HoOKham.

\section{Thinking Cats.}

I HAVE known three cats which behaved as if they thought. The first, a large, sleek tabby, belonged to a private family living in the City. Between 1846 and $185^{8}$ the owner, Mr. I. S., was surprised by his manservant coming to his office at the back of the house in business hours and asking, "Did you ring, sir?" "No, I have not been into the house," was his answer. This occurred repeatedly. At last the man watched, and observed that, the family being in other rooms, the dining room bell rang, and when he answered it the cat ran out of the door. He then purposely shut her into the room. A leather easy chair was so placed that by getting on the seat, and then standing on the arm, she could reach the knob with her front paw; and she continued to practise this accomplishment as often as she was shut up in the room.

The second cat, also a large tabby, lived at Blackheath. Her master often sat up late writing. The cook, a " good old servant," also now and then sat late, sewing or reading, in the kitchen. One night after twelve Mr. H. F. was interrupted by the cat running into the library (the door being open), mewing and clawing him, then running towards the door, and repeating these acts. He got up and followed the cat, which now ran into the kitchen. The cook was sitting asleep close to the fender, a piece of coal had fallen on her dress, and it was burning. No harm happened, thanks to the cat.

The third was a very small, slight cat, white and tabby, a good mouser and bird catcher, and not at all afraid of a rat. On one occasion the servant, exasperated by the trouble caused by the cat's selection of a birthplace for kittens, drowned them all, for which she was duly rebuked. The next family arrived in a suitable corner, but, when two or three days old, disappeared, as well as their mother. As the cat was never allowed to go upstairs, it was supposed that, like another cat once before, she had made a lair in the garden, where she spent most of her time. At dusk the mistress of the house went up to dress for dinner. As soon as she entered her room she heard something fall, and it struck her that the noise was like a cat's jump from a height. Procuring light she found the cat standing by the door. She then saw that the curtains, where folded on the bed, had been a little disturbed, put in her hand, and found three soft warm kittens! They were immediately put into a basket with flannel, and set by the kitchen fire; but as soon as the lady had gone downstairs she met the cat, with a kitten in her mouth, on her way back to the bedroom. Why did she select that room? She was not petted by the lady, nor friendly to her. The housemaid was safe, busy waiting at table.

Debarred from this resource, she hid the kittens again while the family were at dinner, and apparently felt so sure that they were safe, that she went and sat by the kitchen fire, awaiting the usual scraps. Of course a search was made in all likely hiding places and corners frequented by the young people, who were very fond of this cat, and thought she was fond of them. A piteous, faint squealing betrayed the poor little creatures on the floor behind the largest folios in the library. The space above the books was so small that it is difficult to think how the cat got in with a kitten in her mouth, or even without it. This was the one room into which the housemaid seldom came, especially in the evening, as the master sat there. He did not pet the cat at any time, and she took no notice of him.

But though securely hidden, the kittens could hardly have lived in that cold place; their mother seemed to have overlooked their need of warmth. After this failure she submitted to have them kept in the basket in the kitchen.

$$
\text { Y. N. }
$$

\section{Fish.passes and Fish.ponds.}

IN your issue of August 18 , in an article dealing with fish-passes and fisti-ponds, the following statement is made :-

"Much of the information as to the construction of ponds and their inlets and overflows is, of course, ancient, and can be found in such books as the "History of Howietoun" (by the late Sir James Ramsay Gibson Maitland, Bart.).

The above statement may easily cause the incorrect inference that the information in Sir James Ramsay Gibson Maitland's work is now obsolete. Perhaps you may care to make it known that this is, of course, not the case, although no doubt with lapse of time improvements and modifications are introduced. Howietoun Fishery Co.

Howietoun Fishery, Stirling, N.B., October 24.

\section{Average Number of Kinsfolk in each Degree.}

I THANK Dr. Galton for his explanation (p. 626), which only shows how easy it is to make mistakes in things which appear perfectly trivial. The discrepancy can be accounted for, however, more simply still by the fact that families containing boys only have to be left out of account, and therefore in the families which contain at least one girl there are on an average more girls than boys altogether.

G. H. BRYAN.

\section{Misuse of Words and Phrases.}

IT is quite true, as Mr. Basset says, that " in English considerable care is often required in the arrangement of a sentence, so as to avoid ambiguity "; but he seems to go too far when he says that "brevity ought always to be aimed at." Too much brevity will often, as we are warned by Horace, lead to obscurity: "brevis esse laboro: obscurus fio" ; and the absence of inflections and genders renders it impossible to write English in the brief, epigrammatic style that is common in Latin.

To Mr. Basset's rules the following may be advantageously added: that new words of foreign origin should not be employed when English words will suit the purpose as well or better. For instance, autotomic and anautotomic, as applied to curves, are objectionable, because self-cutting and non-self-cutting express precisely the same ideas in simpler and more familiar words. I am at a loss to know on what ground $\mathrm{Mr}$. Basset objects to the phrase "nonsingular cubic curve", does he think the epithet is "uncouth" or "inelegant" or "inaccurate"?

October $3 \mathrm{I}$.
T. B. S. 